\title{
A Psicologia Brasileira nos Ciclos Democrático-Nacional e Democrático-Popular
}

\author{
Filipe Milagres Boechat \\ Universidade Federal de Goiás, GO, Brasil.
}

\begin{abstract}
Resumo: Partindo do pressuposto da vinculação da Psicologia a determinados compromissos de classe, buscaremos evidenciar como sua história articula-se à história da formação social brasileira e às principais ideologias de dois de seus ciclos históricos: o ciclo democráticonacional e o ciclo democrático-popular. Como método, lançaremos mão dos pressupostos, da lógica e dos conceitos provenientes da tradição marxista, especialmente aqueles oriundos das reflexões do marxista sardo Antonio Gramsci. Procuraremos, ainda, apontar de que maneira a Psicologia nascida durante o ciclo democrático-popular, em que pese a contribuição dada à reflexão sobre o caráter ideológico e elitista da Psicologia brasileira, não necessariamente deixou de cumprir, ela também, determinado papel ideológico, seja ao retirar do horizonte de suas análises o núcleo central da teoria social marxista, seja ao promover algumas práticas que pouco contribuem para fornecer às classes subalternas os elementos de que necessitam para potencializar suas lutas radicalmente emancipatórias. Com esse objetivo, esperamos contribuir com alguns apontamentos para a crítica da ideologia do compromisso social da qual esta Psicologia é intimamente solidária, da mesma forma como a Psicologia do ciclo democráticonacional foi intimamente solidária à ideologia nacional-desenvolvimentista.
\end{abstract}

Palavras-chave: Psicologia crítica, História da Psicologia, Ciclo Democrático-Nacional, Ciclo Democrático-Popular, Marxismo.

\section{Brazilian Psychology during the Democratic and National Cycle and the Democratic and Popular Cycle}

\begin{abstract}
Based on the assumption of the relation between Psychology and certain class commitments, we will seek to demonstrate how its history is connected with the history of Brazilian society and with the main ideologies of two of its historical cycles: the Democratic and National cycle and the Democratic and Popular cycle. As a method, we will adopt the premises, logic and concepts deriving from Marxist tradition, especially those emanating from the works of the Sardinian Marxist Antonio Gramsci. At the same time, we will seek to point out how the Psychology born during the Democratic and Popular cycle, notwithstanding its contribution to the reflection on the ideological and elitist character of Brazilian Psychology, not necessarily stopped playing a certain ideological role too, either by wiping the core of the Marxist social theory out of its analysis, or by promoting practices that contribute little to enhance the struggles of the subordinated classes for its radical emancipation. With this purpose, we expect to contribute with some observations to the critique of the ideology of the social compromise, to which this Psychology is closely related, in the same way that Psychology was closely related to the national-developmentalist ideology during the Democratic and National cycle.
\end{abstract}

Keywords: Critical Psychology, History of Psychology, National and Democratic Cycle, Democratic and Popular Cycle, Marxism. 


\title{
La Psicología Brasileña en el Ciclo Democrático- Nacional y en el Ciclo Democrático-Popular
}

\begin{abstract}
Resumen: Partiendo del presupuesto de la vinculación de la psicología a determinados compromisos de clase, buscaremos evidenciar cómo su historia se articula a la historia de la formación social brasileña y a las principales ideologías de sus ciclos históricos: el ciclo democrático-nacional y el ciclo democrático-popular. Como método, recorreremos a los presupuestos, la lógica y los conceptos provenientes de la tradición marxista, especialmente aquellos provenientes de las reflexiones del marxista sardo Antonio Gramsci. Buscaremos, además, señalar cómo la psicología nacida durante el ciclo democrático-popular, no obstante la contribución que dio a la reflexión sobre el carácter ideológico y elitista de la psicología brasileña, no necesariamente dejó de cumplir, también, determinado papel ideológico, al retirar del horizonte de sus análisis el núcleo central de la teoría social marxista, o al promover algunas prácticas que poco contribuyen a proporcionar a las clases subalternas los elementos que necesitan para potenciar sus luchas radicalmente emancipatorias. Con ese objetivo, esperamos contribuir con algunas observaciones a la crítica de la ideología del compromiso social de la cual esta psicología es íntimamente solidaria, de la misma forma que la psicología del ciclo democrático-nacional fue íntimamente solidaria a la ideología nacional-desarrollista.
\end{abstract}

Palabras claves: Psicología Crítica, Historia de la Psicología, Ciclo Democrático-Nacional, Ciclo Democrático-Popular, Marxismo.

\section{Introdução}

Neste mesmo periódico, há exatos cinco anos, por ocasião da comemoração dos 50 anos da regulamentação da profissão de psicólogo no Brasil, Antunes (2012) mostrou-nos algumas das contradições presentes no processo de desenvolvimento da Psicologia brasileira. Remetendo-nos às suas condições de produção e apontando suas principais afiliações ideológicas, a autora evidenciou a presença de ideias e práticas psicológicas divergentes em relação às ideias e práticas dominantes em cada um dos períodos considerados (dentre as quais se destacavam aquelas de Manoel Bomfim, Ulysses Pernambucano e Helena Antipoff). Partindo da produção dos saberes psicológicos, no período colonial, e chegando ao processo de regulamentação da profissão, na década de 1960, passando pelo processo de autonomização da Psicologia, entre os séculos XIX e XX, e de sua consolidação institucional, a partir da década de 1930, Antunes também desvelou alguns dos vínculos mais ou menos imediatos que unem a história da Psicologia brasileira ao quadro mais geral da história de nossa formação social.

O recurso de Antunes às condições histórico-sociais de produção das ideias e práticas psicológicas, aos projetos político-ideológicos e seus respectivos compromissos de classe, partiam da convicção de que:

No caso da Psicologia brasileira, faz-se necessário compreendê-la como construção histórica e social, síntese de múltiplas determinações, orientada por determinadas concepções de homem e de sociedade e comprometida com posições de classe e, portanto, contraditória, sendo que o embate entre esses elementos que se opõem produz movimento e possibilita superação (Antunes, 2012, p. 46).

Mais recentemente, realizando apontamentos sobre a história e o desenvolvimento da Psicologia crítica no Brasil, Lacerda Junior (2013) fez, por sua vez, a seguinte observação:

Não é exagero dizer que a Psicologia emergiu associada às classes dominantes da formação social brasileira. Da mesma forma como a Psicologia nos EUA no início do século XX, na busca por legitimidade social, se associou aos setores dominantes da sociedade norte-americana, a Psicologia brasileira soube rapidamente se posicionar diante das lutas de classes (Lacerda Junior, 2013, p. 219). 
Partindo do pressuposto dessa vinculação da Psicologia a determinadas posições de classe, indicada tanto por Antunes (2012) como por Lacerda Junior (2013), buscamos evidenciar, dentro dos limites deste ensaio, de que maneira a história da Psicologia brasileira articula-se à história da formação social brasileira. Particularmente, tentamos mostrar de que maneira a história da Psicologia brasileira articula-se à história política brasileira e, consequentemente, às ideologias hegemônicas de dois de seus últimos ciclos históricos: o ciclo democrático-nacional e o ciclo democrático-popular. Procuramos, ainda, apontar de que maneira uma das variantes de Psicologia crítica nascida no ciclo democrático-popular, em que pese a contribuição dada à reflexão sobre o caráter ideológico e elitista da Psicologia brasileira, não deixou de cumprir determinado papel ideológico ao retirar do horizonte de suas análises o núcleo central da teoria social marxista (Carvalho, 2014) e ao promover algumas práticas que pouco contribuem para fornecer às classes subalternas os elementos de que necessitam para potencializar suas lutas radicalmente emancipatórias. Esperamos, assim, contribuir com alguns apontamentos para a crítica da ideologia do compromisso social (Silva, 2015, 2017), da qual esta forma particular de Psicologia crítica é intimamente solidária, da mesma maneira como a Psicologia nascida no ciclo democrático-nacional foi intimamente solidária à ideologia nacional-desenvolvimentista (Paiva, 1980; Toledo, 1978).

No que concerne, particularmente, às relações entre a história da Psicologia e o ciclo democrático-popular, cumpre assinalar que os apontamentos e as indicações a que chegamos resultam de pesquisa ainda em curso que lança mão, de maneira exploratória, de materiais heterogêneos, como a produção bibliográfica (livros, teses, dissertações, artigos, comunicações etc.) diretamente vinculada aos autores dessa nova forma de Psicologia crítica; materiais textuais e audiovisuais produzidos por associações e instituições do campo psicológico, como o Conselho Federal de Psicologia (CFP), o Conselho Regional de Psicologia de São Paulo (CRP-SP), o Programa de Estudos Pós-graduados em Psicologia Social da Pontifícia Universidade Católica de São Paulo (PEPG-PSO/ PUC-SP), a Associação Brasileira de Psicologia Social (Abrapso); entrevistas com personagens que participaram da criação desses espaços, entre outros.

O método que empregamos para a análise, interpretação e explicação das relações entre a história da Psicologia brasileira e os referidos ciclos históricos fundamentou-se nos pressupostos, na lógica e nos conceitos provenientes da tradição marxista (Netto, 2006, 2011). Como nos interessa deslindar os nexos entre estratégias de dominação de classe e seus correspondentes agentes sociais em determinados ciclos históricos, recorremos a alguns dos conceitos desenvolvidos por Gramsci (1891-1937). Isso porque a participação orgânica de intelectuais na conformação dos blocos históricos, analisada por Gramsci (2000), parece-nos peça-chave para compreendermos como a Psicologia tem participado das estratégias de dominação postas em marcha na história da formação social brasileira, independentemente da consciência e das eventuais boas intenções de seus principais agentes ${ }^{1}$.

Dito isso, resta-nos dizer, nesta breve introdução, que as análises, interpretações e explicações a que chegamos não pretendem ser exaustivas ou definitivas, mas apenas servir à tarefa de desvelamento das contradições imanentes à história da Psicologia brasileira, para que possamos contribuir com a tarefa, necessariamente coletiva, de compreensão da história social e política "como processos constitutivos de nosso objeto de estudo, a Psicologia no Brasil, com a certeza de que muitos estudos e pesquisas são necessários para que essa compreensão se aprofunde e se amplie" (Antunes, 2012, p. 63).

\section{Desenvolvimento}

Uma vez que o objetivo geral deste artigo consiste em apreender algumas das relações entre a história da Psicologia brasileira e os ciclos democrático-nacio-

\footnotetext{
${ }^{1}$ Gramsci oferece uma compreensão mais nuançada das articulações entre as superestruturas e a estrutura social, dos nexos entre ideologias e a conformação de "blocos históricos". Não ignoramos, como salientou Portelli, que "Esse súbito interesse pelo autor dos Quaderni del Carcere e redator de Ordine Nuovo não está [...] isento de segundas intenções e frequentemente se presta a justificar tal ou qual corrente marxista, ou mesmo a seguir um 'novo' teórico que bruscamente vira 'moda', depois de trinta anos de esquecimento" (1977, p. 13). Também não desconhecemos, conforme observou Florestan Fernandes, que "O que se está fazendo com as ideias de Gramsci exige de nós todos um repúdio frontal: as universidades norte-americanas e europeias tentam convertê-lo em um representante amorfo do 'socialismo democrático'” (in Ammann, 1980, p. 12-13). Mas achamos que seria grave erro descartarmos suas contribuições ao estudo das formas contemporâneas de dominação burguesa, sobretudo quando consideramos sua capacidade de articulá-las a uma opção política radical pela emancipação humana das classes subalternas.
} 
nal e democrático-popular, convém definirmos o que entendemos por cada um desses ciclos históricos.

Primeiramente, apresentaremos aquilo que entendemos por ciclo democrático-nacional, indicando alguns aparelhos privados de hegemonia nascidos durante este ciclo que influíram decisivamente sobre a história da Psicologia brasileira. Futuramente, o exame desses aparelhos poderá contribuir para uma compreensão histórico-concreta da forma como se materializou a chamada ideologia do desenvolvimento nacional.

Em seguida, passaremos à apresentação do que entendemos ser o ciclo democrático-popular, seus principais aparelhos privados de hegemonia e o movimento de inflexão conservadora que descreveram, acompanhando o recuo da consciência da classe trabalhadora no descenso do movimento operário, sindical e popular. Criados pela classe trabalhadora ou por iniciativa de intelectuais ligados aos anseios e às lutas das classes subalternas, alguns desses aparelhos sofreram claro processo de transformismo (Gramsci, 2011), contribuindo para o apassivamento das classes subalternas e a consolidação do ciclo democrático-popular a partir do desenvolvimento e difusão da ideologia do compromisso social.

Como procuramos indicar, a história da formação desses aparelhos cruza-se com a história da Psicologia brasileira, o que nos sugere a necessidade de uma história social da Psicologia que considere a totalidade da vida social e as idiossincrasias da formação social brasileira na riqueza de suas mediações, como forma de superar tanto o idealismo, que caracteriza boa parte de sua historiografia, quanto o materialismo mecânico e abstrato.

\section{O ciclo democrático-nacional}

Por ciclo democrático-nacional, compreendemos o período da história brasileira situado entre dois golpes de Estado: o golpe de 1930, que conduziu Getúlio Vargas ao poder, e o golpe empresarial-militar de 1964, que pôs termo às mobilizações populares em torno das Reformas de Base.

Em que pese a natureza política desses dois marcos, o que caracteriza fundamentalmente este ciclo é o intenso e acelerado processo econômico de industrialização e urbanização da sociedade brasileira (consequência, em grande medida, dos impactos em nossa economia da crise mundial de 1929) e sua contrapartida no plano da luta de classes: o ascenso e a organização político-revolucionária da classe trabalhadora.
O conjunto das transformações desse período refletiu-se no pensamento social brasileiro sob a forma de uma ideologia particular: a ideologia do desenvolvimento nacional, também conhecida como nacional-desenvolvimentismo ou, muito simplesmente, desenvolvimentismo (Iasi, 2012a; Paiva, 1980; Toledo, 1978).

De acordo a ideologia do desenvolvimento nacional, a chave para a superação do atraso econômico, político, social e cultural brasileiros encontrar-se-ia no pleno desenvolvimento de relações capitalistas, desenvolvimento este que se encontraria entravado pelo latifúndio e as oligarquias agrárias, de um lado, e pelos interesses e pela atuação das potências imperialistas, por outro (Iasi, 2012a). A ideologia do desenvolvimento nacional, que orientou a atuação política de organizações à direita e à esquerda, foi determinante, como veremos, para a forma assumida pela Psicologia brasileira no período.

\section{O ciclo democrático-nacional e seus aparelhos}

Como dissemos, o ciclo democrático-nacional demandou, por parte das classes dominantes, reordenamentos institucionais e produções ideológicas sobretudo a partir de 1950, como resultado do aprofundamento das contradições imanentes ao processo de industrialização capitalista, das quais o surgimento das Ligas Camponesas dava testemunho (Ammann, 1980).

A história do Brasil desenvolvimentista foi, nesse sentido, a história da indução, por parte do Estado, do processo de modernização capitalista e do desenvolvimento de estratégias visando sua legitimação social, ampliando de forma segmentada os direitos de cidadania e impedindo a organização da classe trabalhadora (Neves, s.d., p. 54, tradução livre).

A implementação dessas estratégias de legitimação social deu-se, em parte, através da criação de algumas instituições deâmbito nacional, algumas das quais por iniciativa do próprio Estado brasileiro. A dominação burguesa exigia a produção de aparelhos privados de hegemonia com o papel de consolidação do bloco histórico nacional-desenvolvimentista. Tratava-se, portanto, daquele movimento em que a sociedade política se encarrega da formação de seus “funcionários" (Gramsci, 2011, p. 207).

O Estado brasileiro buscava legitimar-se formando não apenas seus próprios quadros, mas avançando ideologicamente sobre o conjunto da 
sociedade $\mathrm{civil}^{2}$. Historicamente autocrático e particularista, apresentava-se sob novas formas, como garante da soberania popular e representante legítimo da vontade geral. Em termos gramscianos, a coerção buscava revestir-se de consenso.

Entre as instituições criadas no curso do ciclo democrático-nacional, algumas determinaram sobremaneira o curso da história da Psicologia brasileira. Dentre essas instituições, destacamos o Instituto Nacional de Pedagogia, o Instituto de Seleção e Orientação Profissional (ISOP) e o Instituto Superior de Estudos Brasileiros (ISEB).

Criado em 1937, o Instituto Nacional de Pedagogia transformou-se em Instituto Nacional de Estudos Pedagógicos (INEP) pelo Decreto-Lei n ${ }^{\circ} 580$, de 30 de julho de (Brasil, 1938), tendo Lourenço Filho como seu primeiro diretor-geral. Durante o ciclo democrático-nacional, ao Instituto competia, entre outras funções, o desenvolvimento da Psicologia aplicada à educação e à orientação e seleção profissionais, tendo papel destacado na difusão dos princípios da pedagogia escolanovista.

O Dicionário Histórico de Instituições de Psicologia no Brasil (Jacó-Vilela, 2011) menciona o Instituto como continuação do Pedagogium, instituição que abrigou o primeiro laboratório de Psicologia experimental do país (Antunes, 2017, p. 68 e ss.).

A importância do INEP para o desenvolvimento da Psicologia brasileira não deve ser desprezada, sobretudo se consideramos o peso conferido à ciência psicológica na definição das diretrizes pedagógicas deste período da história da educação brasileira (Antunes, 2017). Sua importância para a Psicologia não se limitou ao campo da educação. Segundo nos mostrou Antunes, "a Psicologia aplicada à educação e a psicologia aplicada às relações de trabalho constituem-se ambas em campos diversos, porém voltados, pelo menos, em última instância, para objetivos comuns, num mesmo contexto histórico" (2017, p. 110). Esses "objetivos comuns" consistiam na formação da força de trabalho adequada às novas condições de produção da vida social, além da normalização, da higie- nização, moralização e disciplinarização sociais, formação esta operada por profissionais liberais, membros da pequena-burguesia sob direção das classes dominantes.

O ISOP, por sua vez, criado em 1947 pela Fundação Getulio Vargas (FGV, criada em 1944), teve papel decisivo no desenvolvimento da Psicologia brasileira do período. Segundo Antunes (2012, p. 58), o ISOP "foi base para o desenvolvimento de pesquisas, de diversas modalidades de intervenção psicológica e de formação de profissionais especialistas nas questões psicológicas relacionadas à organização do trabalho".

Na primeira edição do periódico Arquivos Brasileiros de Psicotécnica, órgão de divulgação do instituto, lia-se que sua criação objetivava "contribuir para o ajustamento entre o trabalhador e o trabalho, mediante o estudo científico das aptidões e vocações do primeiro e dos requisitos psicofisiológicos do segundo" (Fundação Getúlio Vargas, 1949, p. 7). Assentava-se sobre a convicção de que "a preponderância do fator humano entre as questões ligadas à racionalização do trabalho constitui, hoje em dia, ponto de aceitação pacífica" (FGV, 1949, p. 7-16). Na apresentação do periódico, assim se expressara o então presidente da FGV, Luiz Simões Lopes:

A publicação destes Arquivos visa conclamar os que estudam o assunto do ponto de vista científico, os profissionais da psicotécnica, os nossos administradores, empregadores, nas atividades públicas ou privadas, "consumidores" do fator humano, que tanto necessitam de mão de obra adequada, encetarmos, juntos, uma forte campanha de aumento da produção nacional, de maior rendimento, de maior felicidade no trabalho, através da Seleção e da Orientação Profissional (FGV, 1949, p. 2).

O ISEB foi criado em 1955. Ao Instituto coube a formulação da ideologia do desenvolvimento nacional (Toledo, 1978). Segundo a ideologia nacional-desenvolvimentista isebiana ${ }^{3}$, as formações sociais perifé-

\footnotetext{
${ }^{2}$ Como observou Gramsci, "As classes dominantes precedentes eram essencialmente conservadoras, no sentido de que não tendiam a assimilar organicamente as outras classes, ou seja, a ampliar 'técnica' e ideologicamente sua esfera de classe: a concepção de casta fechada” (Gramsci, 2011, p. 279). Com o desenvolvimento do capitalismo, no entanto, "A classe burguesa põe-se a si mesma como um organismo em contínuo movimento, capaz de absorver toda a sociedade, assimilando-a assim a seu nível cultural e econômico; toda a função do Estado é transformada: o Estado torna-se 'educador" (Gramsci, 2011, p. 279).

${ }^{3}$ Se é verdade que o nacional-desenvolvimentismo é gestado ao longo de toda a Era Vargas, seu nascimento data da década de 1950, impulsionado, no plano internacional, pelas vicissitudes do pós-guerra e, no plano nacional, pelo processo acelerado de industrialização. Esse processo de desenvolvimento das relações capitalistas nos países da periferia do sistema mundial visava não apenas frear o avanço mundial do socialismo, como baratear o valor da força de trabalho no centro do sistema e a ampliar suas reservas de "acumulação primitiva" (Oliveira, 2013, p. 109). Caberia lembrar que datam desse período a Conferência de Bretton Woods, em 1944, que resultou na criação do Fundo Monetário Internacional (FMI), do Banco Mundial (BM), da Organização das Nações Unidas (ONU), bem como sua Comissão Econômica para a América Latina e o Caribe (Cepal), instituições que desempenharam papel crucial durante a "guerra fria", sobretudo no que se refere à política dos EUA para a América Latina.
} 
ricas estariam marcadas por conflitos entre setores "tradicionais", "atrasados", comprometidos com as estruturas de dominação "coloniais ou semicoloniais", e setores "progressistas" ou "modernos", empenhados na modernização, industrialização e emancipação nacionais (Toledo, 1978).

Vejamos, na seção seguinte, de que maneira a ideologia do desenvolvimento nacional foi determinante para a Psicologia brasileira deste período, delimitando seus objetos, definindo suas prioridades e orientando suas ações.

\section{A Psicologia brasileira no ciclo democrático-nacional}

Como nos mostrou Antunes, a Psicologia brasileira esteve empenhada, desde a chegada da corte portuguesa, na higienização, moralização e normalização da sociedade brasileira. A partir de 1930, a Psicologia inicia seu processo de institucionalização. Daí em diante, ela estará engajada na produção de "um novo homem, adequado aos novos tempos" (Antunes, 2012, p. 53), auxiliando as classes dominantes em seus esforços de diferenciação e disciplinarização da força de trabalho, segundo uma "concepção política de 'colaboração de classe', eliminando as contradições e conflitos presentes na relação entre capital e trabalho" (Antunes, 2017, p. 85).

O psicólogo formado nos quadros deste ciclo histórico era considerado como agente de modernização e desenvolvimento nacional. "Racionalizando" as relações de trabalho, educação e assistência; empregando técnicas e procedimentos cientificamente qualificados, o psicólogo contribuiria não apenas para o progresso da Nação, como para a desalienação do povo brasileiro (Toledo, 1978). A Psicologia brasileira, portanto, subordinava-se à ideologia do desenvolvimento nacional, que influenciava setores tanto à esquerda quanto à direita do espectro político.

Essa subordinação não se limitou aos quadros do ciclo democrático-nacional. Referindo-se ao momento da regulamentação da profissão, em 1962, e às décadas que se seguiram ao golpe de 1964, Scarparo e Guareschi (2007, p. 100) observaram que "as práticas psicológicas se consolidaram sobre a influência das ideologias desenvolvimentistas, pautadas pela repressão política e pelo patrulhamento ideológico que caracterizaram o Brasil ao longo de quase três décadas de ditadura explícita”.
Entretanto, a partir do final da década de 1960, como parte das agitações que sacudiram o mundo e como resposta à ofensiva do Estado ditatorial sobre as instituições universitárias, mas sobretudo em consequência de mudanças do mercado de trabalho brasileiro, da abertura de novos campos de atuação, e da afluência de novos referenciais teórico-metodológicos, a Psicologia brasileira viu nascer uma forma alternativa (Yamamoto, 1987, 2003, 2007).

Como veremos adiante, essa Psicologia correspondia a um movimento mais geral no seio da sociedade brasileira. Expressão de um ciclo histórico que estava por nascer, ela assumiu a feição das demais expressões do ciclo, compartilhando das linhas mais gerais de seu desenvolvimento.

\section{O ciclo democrático-popular}

Consideramos o ciclo democrático-popular, grosso modo, como o período da história da brasileira aberto no final da década de $1970 \mathrm{com}$ o ascenso das lutas operárias, sindicais e populares contra as políticas de arrocho salarial, o aumento do custo de vida e o rebaixamento real dos salários reais pela inflação, lutas que ganharam destaque com as greves do $\mathrm{ABC}$ paulista. Data do início deste ciclo o surgimento do assim chamado novo sindicalismo, com seu "novo modo de condução das lutas"; das oposições sindicais, "organizações sindicais extraoficiais, fundadas nas comissões de fábricas"; dos movimentos sociais contra as restrições impostas pela forma autocrática assumida pelo Estado burguês desde o golpe de 1964, movimentos esses apoiados, em larga medida, por setores progressistas da Igreja Católica (Meneguello, 1989; Rainho, \& Bargas, 1983; Tumolo, 2002).

No plano internacional, vale lembrar que a década de 1970 assistiu ao golpe no Chile, início do primeiro experimento neoliberal. A crise de acumulação impôs um conjunto de medidas que redundaram na reestruturação dos processos produtivos e das relações de trabalho em escala planetária (Tumolo, 2002). No Brasil, a ofensiva do Capital sobre o Trabalho não tardou em encontrar novas formas de expressão. Como resposta a essa ofensiva, na década de 1980, temos a fundação do Partido dos Trabalhadores (PT), da Central Única dos Trabalhadores (CUT) e do Movimento dos Trabalhadores Rurais Sem Terra (MST). A campanha pelas eleições diretas, que se encerra com a promulgação da Constituição Cidadã, em 1988, marca o desfecho do grande ascenso de massas do período. 
A queda do muro de Berlim, em 1989, a dissolução da URSS e o desmonte do bloco socialista, na década de 1990, sugeriram o triunfo definitivo do capitalismo, dando lugar às ideologias sobre o fim da história, da centralidade do trabalho, da luta de classes e, por fim, da própria ideologia.

Este ciclo histórico, que tem mostrado haver alcançado seu limite (Demier, 2016; Iasi, 2017), caracterizou-se por haver desenvolvido, ele também, uma ideologia, assim como aparelhos voltados à sua elaboração e difusão. A essa ideologia, que apresenta traços de ruptura e de continuidade com a ideologia nacional-desenvolvimentista (Iasi, 2012b; Martins, Prado, Figueiredo, Motta, \& Souza, 2014), tem-se dado o nome de ideologia do compromisso social (Silva, 2015, 2017). Em torno da ideologia do compromisso social, cuja marca principal consiste em condicionar a emancipação humana à radicalização da democracia participativa e, progressivamente, em limitar a ideia de emancipação aos quadros da emancipação política (Lacerda Junior, 2015; Marx, 2010), orbitam os conceitos de cidadania, democracia, inclusão social, justiça social, participação social, bem como o clamor pela defesa e ampliação de direitos através da organização e fortalecimento da sociedade civil e da conquista de políticas públicas e sociais.

Conforme Martins et al. (2014, p. 360), esse ciclo, a princípio,

pauta-se no processo de alargamento da democracia, compreendido como a ampliação progressiva de um conjunto de direitos e de participação política, através da pressão dos movimentos sociais e da ocupação dos espaços no Estado, que se chocariam contra os interesses de nossa classe dominante. É desse choque que emergiria a necessidade do socialismo.

Ao longo do desenvolvimento deste ciclo, em parte devido às derrotas do movimento operário e sindical brasileiro, em parte pela derrota do movimento comunista internacional, o horizonte socialista limitou-se cada vez mais à natureza de simples ideal. Não nos ocuparemos aqui desse movimento de rebaixamento da perspectiva revolucionária que esteve em sua origem, já examinado por Iasi (2012b), Martins et al. (2014), entre outros (Demier, 2016; Figueiredo, 2014). Limitamo-nos à breve apresentação de algumas das objetivações deste ciclo, algumas das quais assumiram a forma de aparelhos privados de hegemonia da classe trabalhadora, responsáveis, como tais, por contribuir para a formação e atuação de seus intelectuais orgânicos na luta pela conquista da hegemonia, isto é, pela direção intelectual e moral de seus aliados no seio das demais classes subalternas.

\section{O ciclo democrático-popular e seus aparelhos}

Um dos aparelhos privados de hegemonia mais significativos desse novo ciclo é o PT. Nascido das lutas do assim chamado "novo sindicalismo", o partido soube aglutinar em torno de si todo um conjunto de forças sociais. Enquanto polo aglutinador, as bandeiras empunhadas pelo "novo sindicalismo" foram decisivas para a conformação do grande bloco de forças que pôs em xeque o regime ditatorial, inaugurando o ciclo democrático-popular.

Analisando os principais documentos oficiais do partido, Iasi (2012b) mostrou o movimento que redundou na acomodação do PT aos limites da ordem burguesa e, segundo Figueiredo (2014, p. 64), à retomada de velhos "fetiches desenvolvimentistas e nacionais". Como sintetizou Musse,

Organizado a partir das lutas concretas, sindicais, como um movimento político de afirmação da independência e autonomia da classe operária, o PT apresenta-se, inicialmente, como representante da "classe trabalhadora"; depois, do conjunto dos "trabalhadores"; em seguida do "povo"; e, por fim, dos "cidadãos". A passagem da "classe" à "nação" atesta a prevalência da estratégia do "gradualismo reformista" e a subordinação à tática eleitoral, que redefiniram o horizonte social, político e econômico do projeto partidário (apud Iasi, 2012b, p. 10).

A CUT é outra das expressões significativas do ciclo democrático-popular. Criada em 1983, ela deu forma institucional ao "novo sindicalismo", servindo de braço sindical do PT desde então. Tumolo (2002) desvelou os momentos do movimento que levou a formação sindical da maior central sindical do país a transformar-se numa mescla de formação instrumental e qualificação profissional. Esse movimento correspondia à reorientação estratégica da Central, como resposta política às transformações do mundo do tra- 
balho e das derrotas do movimento sindical. A CUT acabaria por sucumbir às exigências imediatas postas pela sociabilidade do capital, abandonando paulatinamente uma perspectiva classista e anticapitalista, substituindo-a pela ideia do "sindicato cidadão".

O importante agora é destacar que uma das variantes de Psicologia crítica nascida no ciclo democrático-popular desempenhou papel de peso na instrumentalização ideológica e na consolidação deste ciclo, acompanhando mais ou menos sincronicamente o movimento de inflexão conservadora realizado pelas demais objetivações a que fizemos referência. Referimo-nos à Psicologia crítica nascida nas dependências da Pontifícia Universidade Católica de São Paulo (PUC-SP), aquela que veio a se desenvolver, fundamentalmente, em torno dos trabalhos e da atividade político-pedagógica de Silvia Lane (1933-2006) e que Carvalho (2014) analisou, recentemente, sob a rubrica da "Escola de São Paulo de Psicologia Social".

\section{A Psicologia no ciclo democrático popular}

Do ciclo democrático-popular à "Psicologia democrática e popular"

A participação ativa da PUC-SP no processo de formação do PT e, consequentemente, na consolidação do ciclo democrático-popular, é fato notório. Conforme observou Meneguello,

Fundamentalmente em São Paulo, a maioria dos intelectuais envolvidos nas discussões partidárias eram elementos ligados ao CEBRAP (Centro Brasileiro de Análise e Planejamento), CEDEC, (Centro de Estudos de Cultura Contemporânea), UNICAMP (Universidade Estadual de Campinas - SP), USP (Universidade de São Paulo) e PUC-SP (Pontifícia Universidade Católica de São Paulo) (Meneguello, 1989, p. 61).

No que diz respeito à participação da Psicologia da PUC-SP, esta foi mediada, em grande parte, pelo PEPG-PSO. Criado no início da década de 1970, o PEPG-PSO aglutinou professores de Psicologia e psicólogos avessos à Psicologia "tradicional". Segundo Bock, que fora orientanda de Lane, ex-diretora da Faculdade de Psicologia da PUC-SP, ex-presidente do Conselho Federal de Psicologia por três gestões e atual presidente do Instituto Silvia Lane - Psicologia e Compromisso Social, essa nova forma de Psicologia estaria marcada pelo rechaço à Psicologia "tradicional", considerada elitista, individualista e positivista (Bock, 1999).

Essa nova forma de Psicologia veio a ser sistematizada com a criação do PEPG-PSO e, posteriormente, da Abrapso. A criação desses dois espaços deu-se em contexto de franco acirramento da luta de classes, em que "a luta pelo acesso aos ganhos da produtividade por parte das classes menos privilegiadas transforma-se necessariamente em contestação ao regime, e a luta pela manutenção da perspectiva da acumulação transforma-se necessariamente em repressão" (Oliveira, 2013).

O PEPG-PSO iniciou suas atividades num clima de intensa fermentação social, às vésperas da crise econômica que acabaria por repercutir sobre os rumos do regime militar. O programa dava prosseguimento à experiência inovadora realizada, anos antes, no curso de Psicologia, sob forte influência de Silvia Lane, com a criação de núcleos que procuravam romper com a rígida separação entre as disciplinas e propunham a articulação entre teoria e prática. (Carvalho, 2014) Procurava-se enfrentar a contrarreforma universitária de 1968, resultado do acordo MEC-USAID, que buscava, entre outros objetivos, despolitizar o ensino brasileiro e desarmar a resistência estudantil (Antunes, 2012; Bock, 1999; Carvalho, 2014; Lacerda Junior, 2013).

A Abrapso, por sua vez, foi criada em 1980, como parte dos esforços de ampliação dessa perspectiva "progressista" em Psicologia. De acordo com os apontamentos de Molón sobre o que veio a chamar de "Psicologia abrapsiana", "A criação da Abrapso é um marco decisivo na orientação da Psicologia Social brasileira em direção à problemática da nossa realidade sócio-econômico-político-cultural (sic)" (2001, p. 53).

Mas essa nova forma de Psicologia brasileira, desenvolvida nas dependências do PEPG-PSO e, posteriormente, também nos encontros regionais e nacionais da Abrapso, sofreu profunda inflexão, de forma análoga ao que se passou com o PT e a CUT. Um dos traços mais marcantes dessa inflexão foi, sem dúvida, a ampliação de seu referencial teórico-metodológico. Assim descreveu Carvalho (2014) essa inflexão:

Tendo substituído o paradigma do trabalho pelo mundo da vida, acatado a autonomização da esfera das objetivações sociais, aberto mão da teoria do valor-trabalho para compreender a 
sociedade a partir das esferas da comunicação (inversão idealista), das relações intersubjetivas e dos valores, anunciado o fim das lutas de classe ou o seu marasmo e abandonado qualquer referência à transformação revolucionária da sociedade por um socialismo ético (ou revolução ética), a Escola de São Paulo ${ }^{4}$ não figura como uma alternativa marxista de psicologia social (Carvalho, 2014, p. 260).

Movimento semelhante de inflexão ocorreu no conjunto dos trabalhos apresentados nos encontros nacionais e regionais da Abrapso, sobretudo a partir da década de 1990. Segundo Molón,

A década de 1990 se caracteriza fundamentalmente pela diversidade de temas e pela pluralidade e diferenciação de enfoques teórico-metodológicos. Dentro disso, ocorre a proliferação dos encontros nacionais e regionais, a intensificação das publicações, as quais oportunizam o surgimento de novas veredas e novos horizontes, e, simultaneamente, constituem novos modos e espaços de atuação e pesquisa em Psicologia Social, norteados por pressupostos epistemológicos, ontológicos e metodológicos semelhantes, orientados pela preocupação ética, ou seja, comprometidos social e politicamente com as transformações da sociedade e com uma vida mais digna para a maioria da população brasileira (Molón, 2001, p. 61).

Essa inflexão acompanhava o processo de redemocratização da sociedade brasileira. Como outras objetivações do ciclo, a Psicologia desenvolvida no interior do PEPG-PSO e da Abrapso sofreu um processo de transformação que se caracterizou por aquilo Lacerda Junior (2015) diagnosticou como uma hegemonia da emancipação política em detrimento da perspectiva marxista da emancipação humana. Partindo de uma perspectiva classista e anticapitalista, essa forma nova de Psicologia abandonou progressivamente o núcleo da teoria social marxiana. Contrapondo-se à Psicologia "tradicional", elitista, individualista e positivista, a Psicologia "progressista" desenvolvida nas dependências do PEPG-PSO e na Abrapso assumiu progressivamente um "historicismo desenfreado" (Toledo, 1978, p. 56-57), deixando ao segundo plano de suas preocupações a análise concreta da formação social brasileira. Produzir um conhecimento que servisse "para o Brasil, ou seja, para todos os brasileiros" (Bock, 2010, p. 253), prescindindo da referência à luta entre as classes sociais fundamentais e de uma clara posição de classe; desenvolver a democracia participativa e a consciência cidadã, opondo os interesses das "elites" aos interesses da "maioria da população", passaria a constituir seu horizonte político-estratégico.

Da Psicologia democrática e popular ao apassivamento Mas, sendo expressão do ciclo democrático-popular, seria natural que essa Psicologia expressasse suas determinações mais gerais. Acontece que essa relação não foi uma relação unilateral. Conforme procuraremos indicar, a Psicologia formulada no seio do PEPG-PSO, desenvolvida e difundida a partir da Abrapso, contribuiu ativamente para o desenvolvimento do ciclo histórico do qual ela é uma das expressões. Sem desconsiderarmos divergências e dissidências no interior deste processo, nossa pesquisa tem indicado que a Psicologia nascida e desenvolvida no interior desses novos aparelhos, forjados por aliados da classe trabalhadora, cumpriu papel ativo no movimento de inflexão e capitulação tanto do PT quanto da CUT, contribuindo para a consolidação do ciclo democrático-popular e, consequentemente, para o fortalecimento de uma forma sutil de dominação burguesa no Brasil.

Tomemos, por exemplo, a entrevista com Pedro Pontual para o jornal do Conselho Regional de Psicologia de SP (Pontual, 2001). Nela, Pontual, que viria a se tornar diretor do Departamento de Participação Social da Secretaria-Geral da Presidência da República do governo Dilma Rousseff, e que, àquela altura, era apresentado como "Psicólogo e educador, discípulo de Paulo Freire e atual secretário de Participação e Cidadania da Prefeitura de Santo André, SP", com "uma trajetória extensa e marcada pelo compromisso social”, depois de confessar sua dívida intelectual para

${ }^{4}$ Não ignoramos a diferença que separa a Psicologia desenvolvida originalmente por Lane, a "Psicologia sócio-histórica”, de proveniência soviética, os trabalhos da "Escola de São Paulo de Psicologia Social" e os trabalhos de autores que, futuramente, nelas buscarão uma referência e legitimidade. Suas continuidades e descontinuidades e a diferença entre suas intencionalidades políticas, algumas das quais foram objeto de análise de Carvalho (2014), serão analisadas noutra ocasião. 
com a Psicologia da PUC-SP, responde o seguinte, ao ser perguntado sobre o que é fazer política:

Fazer política hoje é, para mim, colocar o instrumental profissional que construí, como psicólogo e educador, a serviço do "empoderamento" das pessoas, como indivíduos e como coletividade. Para quê? Primeiro para ampliar, aprofundar e alargar os estreitos limites de nossa democracia. Um país não pode se contentar com o direito de votar nos seus representantes. Isso é importante, uma conquista fundamental, mas democracia é muito mais: significa cidadãos participando das decisões que afetam seu cotidiano, como atores-protagonistas do espaço público. Há muito que se caminhar nesse sentido. Construir esse espaço público, essa esfera pública supõe construir cidadãos ativos, individual e coletivamente. Para mim, fazer política hoje é apostar nisso (Pontual, 2001, n. p.).

A apresentação do entrevistado também nos informa que Pontual "integrou a equipe do Instituto Cajamar, voltado para a formação de lideranças políticas e populares" e "acompanhou Paulo Freire na implantação do Projeto do Mova - Movimento de Alfabetização de Jovens e Adultos - durante o governo de Luíza Erundina na Prefeitura de SP" (Pontual, 2001).

Tomemos agora o artigo de Odair Furtado, intitulado Psicologia e compromisso social - base epistemológica de uma psicologia crítica (1999), no qual o autor, formado nas dependências do PEPG-PSO, ao descrever sua participação no Programa Integrar, da Confederação Nacional de Metalúrgicos da CUT, diz-nos o seguinte:

O curso tem como objetivo fornecer uma formação de caráter geral, que amplie o horizonte cultural do aluno e lhe dê condições de ampliar sua participação social ao mesmo tempo em que discute as condições sociais e históricas que geram o desemprego do trabalhador no Brasil de hoje. Em resumo, trata-se de uma opção pedagógica que se assenta sobre a noção de cidadania e de inclusão social (Furtado, 2000, p. 226-227).

Concluindo seu artigo, Furtado ainda afirma o seguinte:

Evidentemente, não se trata de construirmos uma psicologia classista, voltada exclusivamente para os trabalhadores, para as classes populares. Tal compromisso representa apenas que precisamos romper com uma psicologia que tem sido classista de uma outra forma (Furtado, 2000, p. 226-228).

No caderno de resumos da XXIX Reunião Anual de Psicologia da Sociedade Brasileira de Psicologia, a mesa-redonda $\mathrm{n}^{\circ}$ 6, intitulada "Psicologia Social e do trabalho - a alternativa popular", é igualmente reveladora da hegemonia da emancipação política e o compromisso com o desenvolvimento da democracia participativa, ao qual fizemos referência. Em "A qualificação profissional e a organização dos trabalhadores - o caso do Programa Integrar da CNM/CUT", Furtado diz-nos que

O Programa Integrar, da CNM/CUT de qualificação e requalificação de metalúrgicos desempregados, desenvolvido a partir do convênio com a PUC-SP, foi a experiência piloto de uma política da Confederação Nacional dos Metalúrgicos da CUT para transformar os sindicatos filiados em ‘sindicatos cidadãos'” (Sociedade Brasileira de Psicologia, 1999).

Por último, tomemos um trecho do Relatório Final do I Encontro Nacional de Psicologia: Mediação e Conciliação. No parecer da comissão ad hoc convidada pelo Conselho Federal de Psicologia para recomendações de posicionamento do Sistema Conselhos acerca da temática, lemos que

A mediação permite acordos vantajosos para todos, mas muito mais que isso, favorece o protagonismo e a geração de mundos possíveis onde o confronto decorrente das diferenças - origem dos conflitos - seja conduzido sem gerar desigualdade e sustentar privilégios (Conselho Federal de Psicologia, 2006).

Na introdução do Relatório, a então presidente do Conselho, Ana Bock, "acreditando que haja, na Psicologia, competência acumulada para contribuir com o desenvolvimento de uma cultura de conciliação", informa-nos de que

A mediação de conflitos - o mais popular dos meios consensuais de resolução de controvérsias - é uma prática que valoriza e facilita a inovação e 
provoca mudanças em procedimentos baseados na autonomia da vontade (Conselho Federal de Psicologia, 2006, p. 9-10).

Que nos sugerem esses dados? Sem ignorar que esses trechos não nos dão senão uma parte da realidade, e sem desconsiderar a diversidade que se abriga sob o guarda-chuva do "compromisso social", os resultados mostram-nos que psicólogos declaradamente comprometidos com "o social" na verdade comprometem-se pura e simplesmente com o desenvolvimento da democracia participativa e da cidadania. Implicitamente, contribuem para difundir ilusões sobre a possibilidade de emancipação no interior de uma ordem social que se funda, precisamente, na manutenção da contradição entre a igualdade formal e a desigualdade real.

Caberia perguntar se a Psicologia surgida no ciclo democrático-popular, declaradamente "progressista", ao buscar superar a Psicologia "tradicional" e "elitista", não permanece refém das oposições e dualismos forjados no ciclo histórico democrático-nacional.

Ao que nos parece, a ideologia do compromisso social acaba reencontrando-se com a ideologia do desenvolvimento nacional, sugerindo a necessidade de uma aliança nacional ou de toda a população para a conquista progressiva dos direitos que caracterizam a sociabilidade burguesa.

Os aparelhos criados para sua elaboração e difusão, o PEPG-PSO e a Abrapso, em que pese haverem se constituído, inicialmente, como aliados da classe trabalhadora, comprometidos com a "maioria dos brasileiros", acabam por se sobrepor aos interesses dessa classe. Posteriormente, ao ocuparem os espaços privilegiados de formação política da classe trabalhadora, especialmente o Instituto Cajamar e a CUT, esses intelectuais, sempre imbuídos do "compromisso social", de aliados da classe trabalhadora passam a dirigentes, impondo os interesses de sua classe particular, que não deixam de ser interesses de classes subalternas. Trata-se, no entanto, de interesses tipicamente pequeno-burgueses, na medida em que buscam conciliar aquilo que é estruturalmente inconciliável: os interesses do Capital aos interesses do Trabalho. Supõem a possibilidade e, mais do que isso, a necessidade de um pacto de classes como condição para a emancipação da maioria da população.

Não pretendemos negar que a ideologia do compromisso social e seus aparelhos contribuíram e têm contribuído para o fortalecimento da democracia brasileira e de suas principais instituições. A afluência dos psicólogos para o campo das políticas públicas tem sido uma das marcas desse novo ciclo histórico, e não se pode negar que essa proletarização impôs à Psicologia novos e desafiadores problemas. No entanto, resta saber se, ao promover ativa e conscientemente os valores e os ideais democráticos, os psicólogos do compromisso social não desempenham, à maneira dos psicólogos do desenvolvimento nacional, o papel de intelectuais orgânicos da burguesia no estágio atual de sua supremacia; se a classe média, ao assumir o leme das lutas e impor o lema do compromisso social, realmente o faz em nome da maioria da população brasileira: a classe trabalhadora. Pois o papel dos intelectuais em aliança com as classes subalternas não deve significar a deferência acrítica aos seus interesses, ideias, valores e temores imediatos. Para um intelectual organicamente vinculado com os interesses da classe trabalhadora, não se trata de colocar-se a serviço das classes subalternas, mas de colocar-se a serviço da emancipação das classes subalternas, o que implica, mais do que um simples compromisso "social" ou "ético-político", uma estratégia político-revolucionária que se comprometa declarada e conscientemente com a superação da sociedade de classes. Uma estratégia político-revolucionária que não se comprometa com abstrações como "o social", "o Brasil" ou "a população brasileira", mas com o conjunto daqueles sujeitos sociais concretos que, pelo lugar que ocupam na produção social da vida, possuem a possibilidade de romper as amarras que os afastam do caminho de sua própria emancipação.

\section{Conclusão}

Procurando dar prosseguimento ao trabalho desenvolvido por Antunes (2012), esperamos haver mostrado que as contradições presentes na história da Psicologia brasileira não se limitam ao campo das divergências entre diferentes proposições teóricas e práticas, fazendo-se igualmente presentes no interior mesmo de cada uma dessas proposições. Ao apontarmos os vínculos orgânicos entre a Psicologia brasileira e os ciclos democrático-nacional e democrático-popular, buscamos mostrar de que maneira a Psicologia nascida no último ciclo histórico é solidária de uma ideologia bem determinada, a ideologia do compromisso social, funcional à dominação burguesa na atual etapa do capitalismo no Brasil. 
Gostaríamos de encerrar este artigo, que apenas insinua todo um conjunto de reflexões que estão por vir, com algumas palavras sobre como entendemos o significado desta nossa pesquisa.

Em tempos de forte ofensiva do capital sobre o trabalho, em que a classe trabalhadora se encontra fragilizada e fragmentada, não apenas no Brasil, mas em todo o mundo, convém não alimentarmos ilusões sobre as alternativas a esta ordem social que aliena, desumaniza, e que nos conduz incessantemente para o precipício da barbárie. Desde nossa perspectiva teórica e de nossa opção política, acreditamos que convém superarmos as ideologias que contribuem para aumentar o fosso entre a Psicologia da classe trabalhadora e sua consciência de classe (Martín-Baró, 1985), isto é, entre as ideias, valores, atitudes e sentimentos de nossa classe e a consciência de seus reais interesses no sentido da emancipação humana.

Evidentemente, não esperamos que tais reflexões conduzam, por si só, à emancipação de nossa classe. Mesmo porque, estamos de acordo, "A psicologia não desempenhará nenhum papel decisivo na resolução dos grandes problemas que acometem os povos latino-americanos", uma vez que "os dilemas latino-americanos são fundamentalmente de natureza econômica e política e dependem de forças objetivas que estão muito distantes do alcance do psicólogo" (Mar-
tín-Baró, 2002, p. 110). Mas não ignoramos a importância do trabalho teórico e crítico na superação de algumas mistificações que afastam as classes subalternizadas, oprimidas e exploradas, do caminho de sua emancipação.

Por último, gostaríamos de acrescentar que o esforço teórico-crítico de compreensão das contradições de nossa história pouco tem a contribuir para a emancipação humana se não se presta a armar as classes dominadas e fornecer-lhes os instrumentos adequados às suas lutas cotidianas. Uma consciência crítica que desafie as ideologias e as instituições que se prestam à nossa dominação e uma teoria social que deslinde os obstáculos históricos interpostos à nossa emancipação são, sem sombra de dúvidas, elementos fundamentais para todos que lutam contra um inimigo de dimensões como o Capital; mas ainda são pouco se a essa consciência crítica e a essa teoria não se vem somar uma clara opção política pela defesa dos interesses materiais das classes subalternizadas. Como sentenciou Fernandes, "Ser 'intelectual orgânico das classes trabalhadoras' é uma opção política. Mas, não se pode fazer essa opção e ficar numa 'prática teórica' crítica ou rebelde que se compõe com a reprodução da ordem burguesa e com o Estado capitalista" (Ammann, 1980, p. 13).

\section{Referências}

Ammann, S. B.. (1980). A ideologia do desenvolvimento de comunidade no Brasil. São Paulo, SP: Cortez.

Antunes, M. A. M. (2012). A Psicologia no Brasil: um ensaio sobre suas contradições. Psicologia: Ciência e Profissão, 32(spe), 44-65. https://doi.org/10.1590/S1414-98932012000500005

Antunes, M. A. M. (2017). A psicologia no Brasil: leitura histórica sobre sua constituição. São Paulo, SP: Educ.

Bock, A. M. B. (1999). Aventuras do Barão de Münchhausen na Psicologia. São Paulo, SP: Cortez.

Brasil (1938, 30 de julho). Lei no 580, de 30 de julho de 1938. Dispõe sobre a organização do Instituto Nacional de Estudos Pedagógicos. Diário Oficial da União.

Carvalho, B. P. (2014). A Escola de São Paulo de Psicologia social: uma análise histórica do seu desenvolvimento desde o materialismo histórico-dialético (Tese de doutorado). Pontifícia Universidade Católica de São Paulo, São Paulo.

Conselho Federal de Psicologia. (2006). Relatório final do I Encontro Nacional de Psicologia: Mediação e Conciliação, Brasília, DF.

Demier, F. (2016). Depois do golpe: a força e a fraqueza da democracia blindada brasileira. Recuperado de http:// blogjunho.com.br/depois-do-golpe-a-forca-e-a-fraqueza-da-democracia-blindada-brasileira/\#_ftnref1

Fundação Getúlio Vargas - FGV. (1949). O Instituto de Seleção e Orientação Profissional da Fundação Getúlio Vargas. Arquivos Brasileiros de Psicotécnica, 1(1), 7-16.

Figueiredo, I. M. (2014). Capital-imperialismo subalterno e dependente e programa democrático e popular. Rebela, 3(3), 394-424. Recuperado de http://rebela.emnuvens.com.br/pc/article/view/169/349 
Furtado, O. (2000). Psicologia e compromisso social: base epistemológica de uma psicologia crítica. PSI - Revista de Psicologia Social e Institucional, 2(2), 217-229. Recuperado de http://www.uel.br/ccb/psicologia/revista/ artigo\%205.pdf

Gramsci, A. (2000). Cadernos do cárcere (vol. 2). Rio de Janeiro, RJ: Civilização Brasileira.

Gramsci, A.. (2011). O leitor de Gramsci: escritos escolhidos 1916-1935. Rio de Janeiro, RJ: Civilização Brasileira.

Iasi, M. L. (2012b). As metamorfoses da consciência de classe: o PT entre a negação e o consentimento (7a ed). São Paulo, SP: Expressão Popular.

Iasi, M. L. (2012a). Democracia de cooptação e o apassivamento da classe trabalhadora. In E. Salvador (Org.), Financeirização, fundo público e política social (pp. 273-312). São Paulo, SP: Cortez.

Iasi, M. L. (2017). Política, estado e ideologia na trama conjuntural. São Paulo, SP: ICP.

Jacó-Vilela, A. M. (Org.). (2011). Dicionário histórico de instituições de Psicologia no Brasil. Rio de Janeiro, RJ: Conselho Federal de Psicologia.

Lacerda Junior, F. (2013). Capitalismo dependente e a psicologia no Brasil: das alternativas à psicologia crítica. Teoría y Crítica de la Psicología, 3, 216-263.

Lacerda Junior, F. (2015). Podem as políticas públicas emancipar? In A. F. Lima, D. C. Antunes, \& M. G. A. Calegare (Orgs.), Psicologia social e os atuais desafios ético-políticos no Brasil (pp. 110-127). Porto Alegre, RS: ABRAPSO.

Martín-Baró, I. (1985). Acción y ideología: Psicología social desde Centroamérica (2a ed.). El Salvador: UCA.

Martín-Baró, I. (2002). La psicología política latinoamericana. In G. Pacheco, \& B. Jiménez (Eds.), Ignacio Martín-Baró (1942/1989): Psicología de la liberación para América Latina (pp. 91-114). Guadalajara: Universidad de Guadalajara.

Martins, C., Prado, F. C., Figueiredo, I. M., Motta, S., Souza, V. N. (2014). A “estratégia democrática e popular” e um inventário da esquerda revolucionária. Marx e o marxismo, 2(3), 357-381.

Marx, K. (2010). Sobre a questão judaica. São Paulo, SP: Boitempo.

Meneguello, R. (1989). PT: a formação de um partido, 1979-1982. Rio de Janeiro, RJ: Paz e Terra.

Molón, S. I. (2001). A Psicologia social abrapsiana: apontamentos históricos. Interações, 6(12), 41-68.

Netto, J. P. (2006). O que é marxismo (9a ed.). São Paulo, SP: Brasiliense.

Netto, J. P. (2011). Introdução ao estudo do método de Marx. São Paulo, SP: Expressão Popular.

Neves, L. M. W. (Org.) Una derecha para lo social y una izquierda para el capital: intelectuareles de la nueva pedagofía de la hegemonía en Brasil. Recuperado de http://www.epsjv.fiocruz.br/sites/default/files/direita_para_o_social.pdf

Oliveira, F. (2013). Crítica à razão dualista: o ornitorrinco. São Paulo, SP: Boitempo.

Paiva, V. P. (1980). Paulo Freire e o nacionalismo-desenvolvimentista. Rio de Janeiro, RJ: Civilização Brasileira.

Programa de Estudos Pós-graduados em Psicologia Social. (2002). Apontamentos para uma história do Programa de Pós-Graduação em Psicologia Social: Pontifícia Universidade Católica de São Paulo. 1972-2002. São Paulo, SP: PUC-SP.

Pontual, P. (2001). Um olhar plural sobre a realidade. Jornal PSI, 19(128). Recuperado de http://www.crpsp.org.br/ portal/comunicacao/jornal_crp/128/frames/fr_dialogos.aspx

Portelli, H. (1977). Gramsci e o bloco histórico. Rio de Janeiro, RJ: Paz e Terra.

Prado Junior, C., Fernandes, F. (2007). Clássicos sobre a revolução brasileira. São Paulo, SP: Expressão Popular.

Rainho, L. F., \& Bargas, O. M. (1983). As lutas operárias e sindicais dos metalúrgicos em São Bernardo (1977-1979). São Bernardo do Campo, SP: Fundo de Greve.

Scarparo, H. B. K., \& Guareschi, . N. M. F. (2007). Psicologia social comunitária profissional. Psicologia \& Sociedade, 19(spe2), 100-108. .

Silva, D. O. (2015). Formação, ideologia e emancipação: nexos com as diretrizes curriculares (2004 e 2011) para os cursos de graduação em Psicologia (Dissertação de mestrado). Universidade Federal de Goiânia, Goiânia. 
Psicologia: Ciência e Profissão 2017 v. 37 (núm. esp.), 57-70.

Silva, D. O.. (2017). Metamorfoses da ideologia do compromisso social na psicologia no Brasil. Comunicação oral. In Anais do I Encontro de História Social da Psicologia, Goiânia, Goiás.

Sociedade Brasileira de Psicologia. (1999). Resumos de Comunicações Científicas do XXIX Reunião Anual, Ribeirão Preto, SP.

Toledo, C. N. (1978). ISEB: fábrica de ideologias (2a ed.) São Paulo, SP: Ática.

Tumolo, P. S. (2002). Da contestação à conformação: a formação sindical da CUT e a reestruturação capitalista. Campinas, SP: Editora da UNICAMP.

Yamamoto, O. H. (1987). A crise e as alternativas da Psicologia. São Paulo, SP: Edicon.

Yamamoto, O. H. (2003). Questão social e políticas públicas: revendo o compromisso da Psicologia. In A. M. B. Bock (Org.), Psicologia e o compromisso social (pp. 37-54). São Paulo, SP: Cortez.

Yamamoto, O. H. (2007). Políticas sociais, "terceiro setor" e "compromisso social": perspectivas e limites do trabalho do psicólogo. Psicologia \& Sociedade, 19(1), 30-37. https://doi.org/10.1590/S0102-71822007000100005

\section{Filipe Milagres Boechat}

Doutor em Psicologia pela Universidade Federal do Rio de Janeiro. Professor do Programa de Pós-graduação em Psicologia da Universidade Federal de Goiás. Membro da Rede Ibero-americana de Pesquisadores em História da Psicologia, do GT de História Social da Psicologia da ANPEPP, do Núcleo de Educação Popular 13 de maio, do Núcleo de Estudos e pesquisas Crítica, Insurgência e Emancipação (CRISE) e do Núcleo de Estudos e Pesquisas Avançadas - Ética e Política Emancipatória.

E-mail: filipeboechat@ufg.br

Endereço para envio de correspondência:

Faculdade de Educação. Rua 235, s/n, Setor Leste Universitário, 74605-050

Recebido 30/06/2017

Reformulação 03/10/2017

Aprovado 06/10/2017

Received 06/30/2017

Reformulated $10 / 03 / 2017$

Approved 10/06/2017

Recebido 30/06/2017

Reformulado 03/10/2017

Aceptado 06/10/2017

Como citar: Boechat, F. M. (2017). A Psicologia brasileira nos ciclos democrático-nacional e democrático-popular. Psicologia: Ciência e Profissão, 37(n. spe), 57-70. https://doi.org/10.1590/1982-3703040002017

How to cite: Boechat, F. M. (2017). Brazilian Psychology during the democratic and national cycle and the democratic and popular cycle. Psicologia: Ciência e Profissão, 37(n. spe), 57-70.

https://doi.org/10.1590/1982-3703040002017

Cómo citar: Boechat, F. M. (2017). La Psicología brasileña en el ciclo democráticonacional y en el ciclo democrático-popular. Psicologia: Ciência e Profissão, 37(n. spe), 57-70. https://doi.org/10.1590/1982-3703040002017 